\title{
Comparison of three options for biodiesel production from waste vegetable oil
}

\author{
A. A. Refaat \& S. T. El Sheltawy \\ Cairo University, Egypt
}

\begin{abstract}
Biodiesel production deserves continued study and optimization of production procedures due to its environmentally beneficial attributes and its renewable nature. From a waste-management standpoint, production of biodiesel from used cooking oil is environmentally beneficial since it provides a cleaner way of disposing of these products than is typically the case. Biodiesel produced by basecatalyzed transesterification of vegetable oil is usually performed in batch reactors where the required energy is provided by heating accompanied by mechanical mixing. Using this technique, the best yield percentage was obtained using a methanol/oil molar ratio of $6: 1$, potassium hydroxide as the catalyst (1\%), and $65^{\circ} \mathrm{C}$ temperature for one hour. Alternatively, ultrasonication can provide an effective way to attain the required mixing while providing the necessary activation energy. It was concluded that transesterification by low frequency ultrasound $(20 \mathrm{kHz})$ offered a lot of advantages over the conventional classical procedure. It proved to be efficient (biodiesel yield up to 98-99\%), as well as time and energy saving (dramatic reduction of reaction time to $5 \mathrm{~min}$, compared to one hour or more using conventional batch reactor systems, and a remarkable reduction in static separation time to 25 min, compared to 8 hours). The third option studied was the application of microwave irradiation. The application of radio frequency microwave energy offered a fast, easy route to this valuable biofuel with advantages of enhancing the reaction rate and improving the separation process. The methodology allowed for the use of high FFA content feedstock, including used cooking oil, hence reducing the cost of production, which constitutes a major hurdle towards widespread commercialization of biodiesel.
\end{abstract}

Keywords: biodiesel, waste vegetable oil, transesterification, optimization, ultrasonication, microwave. 


\section{Introduction}

The three basic methods of ester production from oils/fats are base-catalyzed transesterification, acid-catalyzed esterification, and enzymatic catalysis. The most commonly used method of which is the base-catalyzed transesterification technique as it is the most economical process [1]. Transesterification is an equilibrium reaction and the transformation occurs essentially by mixing the reactants. However, the presence of a catalyst accelerates considerably the adjustment of the equilibrium [2]. Methanolysis with 1\% wt. potassium hydroxide catalyst resulted in successful conversion giving the best yields and viscosities of the esters [3].

The stoichiometric reaction requires $1 \mathrm{~mol}$ of a triglyceride and $3 \mathrm{~mol}$ of alcohol. However, an excess of alcohol is used to increase the yields of the alkyl esters and to allow its phase separation from the glycerol formed [4]. The optimum methanol/oil molar ratio was found to be $6: 1$ [3].

While transesterification is well-established and becoming increasingly important, there remains considerable inefficiencies in existing transesterification processes. In conventional heating of a transesterification process (batch, continuous, and super critical methanol process), heat energy is transferred to the raw material through convection, conduction and radiation from the surfaces of the raw material. Thus, the conventional heating consumes more energy and take long preheat and reaction time, optimally 1 hour [3], to produce over 95 percent conversion yield biodiesel product.

Since this reaction can only occur in the interfacial region between the liquids and also due to the fact that fats and alcohols are not totally miscible, transesterification is a relatively slow process. As a result, a vigorous mixing is required to increase the area of contact between the two immiscible phases and thus to produce an emulsion [5]. Previous research has indicated that ultrasonication provides the mechanical energy for mixing and the required energy for initiating the transesterification reaction [6-10]. Low frequency ultrasonic irradiation is a useful tool for emulsification of immiscible liquids [11]. The collapse of the cavitation bubbles disrupts the phase boundary and causes emulsification by ultrasonic jets that impinge one liquid to another [12].

An alternative energy stimulant, "microwave irradiation", can be used for the production of the alternative energy source, biodiesel. In the electromagnetic radiation spectrum, the microwave radiation region is located between infrared radiation and radio waves. Microwaves (MW) have wavelengths of $1 \mathrm{~mm}-1 \mathrm{~m}$, corresponding to frequencies between $0.3-300 \mathrm{GHz}$. In general, in order to avoid interference, industrial and domestic microwave apparatus are regulated to 12.2 $\mathrm{cm}$, corresponding to a frequency of $2.45 \mathrm{GHz}$, but other frequency allocations do exist [13]. Microwaves, a non-ionizing radiation incapable of breaking bonds, are a form of energy and not heat and are manifested as heat through their interaction with the medium or materials wherein they can be reflected (metals), transmitted (good insulators that will not heat) or absorbed (decreasing the available microwave energy and rapidly heating the sample) [14]. Microwave heating compares very favourably over conventional methods, where heating can be 
relatively slow and inefficient because transferring energy into a sample depends upon convection currents and the thermal conductivity of the reaction mixture [15].

\section{Materials and methods}

The complete methodology of the conventional mixing technique was discussed in detail in a previous study by Refaat et al. [3] in which two different biodiesel fuels, obtained from waste cooking oils with different previous uses, were investigated and neat sunflower oil was used as a reference. The experiments have been run in triplicate; each set of operation conditions was conducted three times, once with neat sunflower oil used as a reference and twice with waste vegetable oils (WVOs) obtained from two different sources: one collected from a house (domestic waste vegetable oil - DWVO) and the other from a fast-food popular restaurant (Restaurant waste vegetable oil - RWVO). Methanol was the alcohol of choice: Methanol (Analytical) El-Nasr Pharmaceutical Chemicals Co. (ADWIC) Mwt. 32.04 Assay 99.8\%. Both $\mathrm{KOH}$ and $\mathrm{NaOH}$ were used in that study: $\mathrm{NaOH}$ pellets purified SISCO Research Laboratories PVT Ltd - India KOH pellets purified Thann-Fransu. The method applied in that study was the alkalicatalyzed transesterification. The transesterification process was studied at two catalyst loadings $(0.5 \%$ and $1.0 \% \mathrm{KOH}$ wt./wt.), two reaction temperatures $(25$ and $\left.65^{\circ} \mathrm{C}\right)$ and three alcohol-to-oil molar ratios (3:1, 6:1 and 9:1). Basically, methanol was the alcohol of choice and $\mathrm{KOH}$ was used as the catalyst. The production methodology followed was obtained by researching current methods of small-scale production. Potassium or sodium methoxide solution was prepared freshly by mixing a predetermined amount of methanol (20\% by weight of oil) with $\mathrm{KOH}$ or $\mathrm{NAOH}(1.0 \%$ by weight of oil) in a container. The reaction was carried out for $1-3 \mathrm{~h}$. under reflux at $60-70^{\circ} \mathrm{C}$. Stirring was started with the reaction at the moment of adding potassium or sodium methoxide solution. After the predetermined reaction time, the mixture was carefully transferred to a separating funnel and allowed to stand there overnight. The lower layer (glycerol, methanol and most of the catalysts) was drained out. The upper layer (methyl esters, some methanol and traces of the catalyst) was then cleaned thoroughly by washing with warm $\left(50^{\circ} \mathrm{C}\right)$ de-ionized water. The methyl ester was then dried with anhydrous $\mathrm{Na}_{2} \mathrm{SO}_{4}$.

The optimum parametric conditions obtained from the conventional technique were applied again using ultrasonication and also microwave irradiation in order to compare the three systems. Ultrasonic mixing was performed with an ultrasonic processor (VC 100, Sonics \& Materials Inc., USA). This processor uses electric excitation to generate ultrasound, which is transmitted into the liquid mixture via a titanium probe that causes mixing and provides the energy for the transesterification. The processor operates at 100 watts, $20 \mathrm{kHz}$ frequency. The amplitude and the pulse for the reaction can be adjusted from $0-100 \%$. Process parameters, such as amplitude, pulse, operating time were modulated using the control knobs. 
Several examples of microwave irradiated transesterification methods have been reported using adapted domestic ovens to use them as flow systems [16] or batch laboratory ovens [17] but only moderate conversions were obtained. A more recent study used homogeneous catalysis, both in a batch and in a flow system [18]. Leadbeater and Stencel [19] reported the use of microwave heating as a fast, simple way to prepare biodiesel in a batch mode. This was followed by a continuous-flow approach allowing for the reaction to be run under atmospheric conditions and performed at flow rates of up to $7.2 \mathrm{~L} / \mathrm{min}$ using a $4 \mathrm{~L}$ reaction vessel [20]. In this study, a scientific microwave with advanced vessel technology was used. This allowed fast vessel heating with homogeneous microwave distribution throughout the cavity. The oven used is Start S (Milestone), Milestone Inc. (USA). The normal pressure glass reactor is complete with a $500 \mathrm{ml}$ flask and reflux condenser. The oven is supplied with a color touch screen controller that enables creation, storage and use of time-vs.-temperature or time-vs.-power reaction profiles. The output microwave power is adjustable up to 1200 watts, controlled via microprocessor. The temperature was adjusted to $65^{\circ} \mathrm{C}$, a methanol/oil molar ratio of $6: 1$ was employed and potassium hydroxide (1\%) was used as a catalyst. The oil was preheated to the desired temperature of $65^{\circ} \mathrm{C}$ using the microwave unit. The alcohol-catalyst mixture was then fed into the flask through the condenser. The output power was adjusted to 500 watts and the mixture was irradiated under reflux applying different reaction times of 30, 60, 90, $120,150,180$ and 240 seconds.

$\mathrm{GC}$ analysis was undergone for all the samples using Agilent $5975 \mathrm{GC} / \mathrm{MS}$ System, Agilent Technologies (USA).

\section{Results and discussion}

The results obtained by applying the conventional technique were discussed in detail in a previous study by Refaat et al. [3]. From the results, it was clear that the produced biodiesel fuel was within the recommended standards of the biodiesel fuel with $96.15 \%$ yield. Biodiesel produced from waste vegetable oil was comparable in composition, similar in calorific value to biodiesel produced from refined sunflower oil.

A comparison held between the reaction time, static separation time and yield $\%$ on using ultrasonic mixing versus mechanical stirring is shown in table 1.

The reaction time was reduced dramatically from 1 hour to 5 minutes $(92 \%)$, the static separation time was reduced remarkably from 8 hours to 25 minutes (95\%) and the yield\% was generally higher.

Application of radio frequency microwave energy enhances the reaction rate for the conversion of triglycerides to biodiesel, and drives the reaction equilibrium toward the production of biodiesel. $100 \%$ biodiesel yield was obtained by applying microwave irradiation for two minutes compared to one hour with the conventional technique. The static separation time was 25 minutes compared to 8 hours with the conventional technique. Application of radio frequency microwave energy further improves product recovery in the separation of the biodiesel product from alcohol and glycerin in the reaction mixture. The results achieved by 
applying microwave irradiation were compared to those obtained by applying the conventional technique (table 2). From these results it is evident that using microwave irradiation reduces the reaction time by about $97 \%$ and the separation time by about $94 \%$.

Table 1: $\quad$ Comparison between mechanical and ultrasonic mixing at optimum conditions.

\begin{tabular}{|l|c|c|c|c|c|c|}
\hline & \multicolumn{2}{|l|}{ Yield\% } & \multicolumn{2}{|c|}{ Reaction time (min) } & \multicolumn{2}{c|}{ Separation time (min) } \\
\hline Oil & $\begin{array}{l}\text { Mechanical } \\
\text { mixing }\end{array}$ & $\begin{array}{l}\text { Ultrasonic } \\
\text { mixing }\end{array}$ & $\begin{array}{l}\text { Mechanical } \\
\text { mixing }\end{array}$ & $\begin{array}{l}\text { Ultrasonic } \\
\text { mixing }\end{array}$ & $\begin{array}{l}\text { Mechanical } \\
\text { mixing }\end{array}$ & $\begin{array}{l}\text { Ultrasonic } \\
\text { mixing }\end{array}$ \\
\hline NVO & 96.15 & 98.94 & 60 & 5 & 480 & 25 \\
WVOD & 95.79 & 98.26 & 60 & 5 & 480 & 25 \\
WVOR & 94.51 & 97.68 & 60 & 5 & 480 & 25 \\
\hline
\end{tabular}

Table 2: $\quad$ Comparison between microwave irradiation and the conventional technique.

\begin{tabular}{|c|c|c|c|}
\hline System & $\begin{array}{c}\text { Reaction Time } \\
(\mathrm{min})\end{array}$ & $\begin{array}{c}\text { Separation time } \\
(\mathrm{min})\end{array}$ & Yield\% \\
\hline Conventional & 60 & 480 & 96 \\
\hline Microwave & 2 & 25 & 100 \\
\hline
\end{tabular}

No substantial differences were obtained with the different origin of the oil. So, using microwave irradiation allows the use of high free fatty acid (FFA) content feed stocks, including animal fats and used cooking oils, in existing transesterification processes by promoting the removal of the fatty acid.

Fig. 1 depicts a comparison between the reaction times using the conventional technique, ultrasonication and microwave irradiation. In fig. 2, the same comparison is held regarding the separation times.

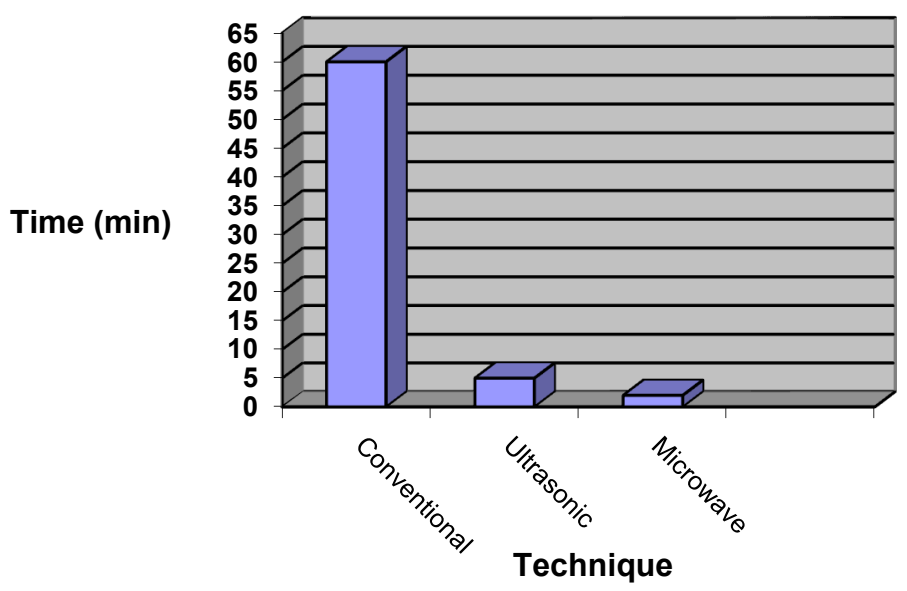

Figure 1: Comparison between the reaction times of the three techniques. 


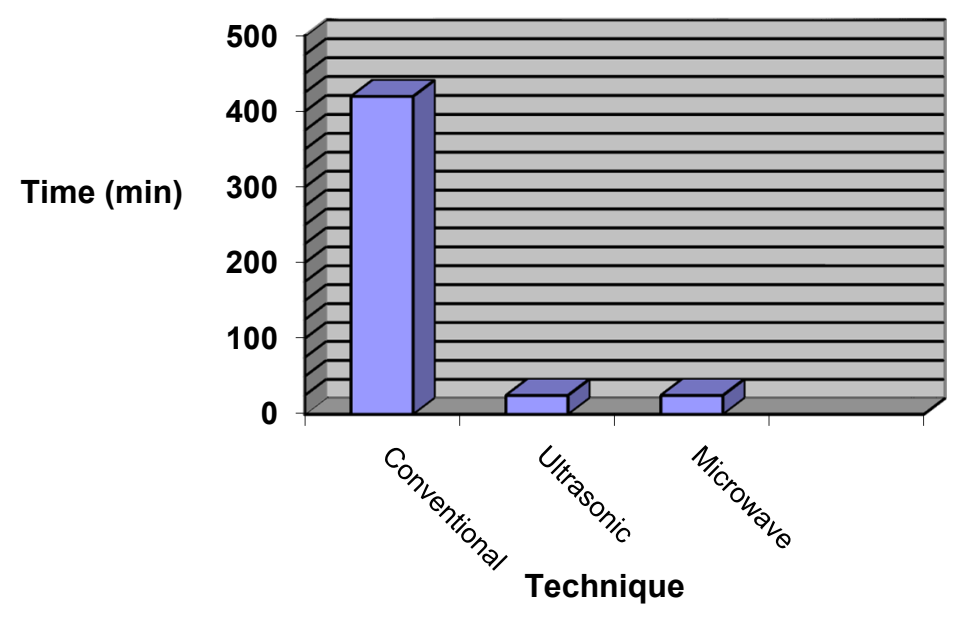

Figure 2: Comparison between the separation times of the three techniques.

\section{Conclusions and recommendations}

From the present study it can be concluded that low frequency ultrasound is an efficient, time saving and economically functional process, offering a lot of advantages over the conventional classical procedure. The reaction time was reduced dramatically from $1 \mathrm{hr}$ to $5 \mathrm{~min}(92 \%)$, the static separation time was reduced remarkably from $8 \mathrm{hr}$ to 25 minutes $(95 \%)$ and the yield\% was generally higher.

At a frequency of $20 \mathrm{kHz}$, the optimum reaction time was found to be 5 minutes and the optimum amplitude was found to be $100 \%$. Biodiesel that met the ASTM D 6751 standard was obtained with yields over $98-99 \%$ at a separation time of only 25 minutes.

The results showed that the application of radio frequency microwave energy offers a fast, easy route to this valuable biofuel with advantages of enhancing the reaction rate and improving the separation process. The methodology allows for the use of high FFA content feedstock, including used cooking oil; hence it helps to reduce the cost of production, which constitutes a major hurdle towards widespread commercialization of biodiesel.

\section{References}

[1] Singh, A.B., He, T.J. \& Van Gerpen, J., Process optimization of biodiesel production using different alkaline catalysts. Applied Engineering in Agriculture, 22(4), pp. 597-600, 2006. 
[2] Ma, F. \& Hanna, M.A., Biodiesel production: a review. Bioresource Technology, 70, pp. 1-15, 1999.

[3] Refaat, A.A., Attia, N.K., Sibak, H.A., El Sheltawy, S.T. \& ElDiwani, G.I., Production optimization and quality assessment of biodiesel from waste vegetable oil. International Journal of Environmental Science and Technology, 5(1), pp. 75-82, 2008.

[4] Schuchardt, U., Serchelia, R. \& Vargas, R.M., Transesterification of vegetable oils: a review. Journal of Brazilian Chemical Society, 9(1), pp. 199-210, 1998.

[5] Singh, A.K. \& Fernando S.D., Catalyzed fast-transesterification of soybean oil using ultrasonication. American Society of Agricultural Engineers, ASAE Annual Meeting, Paper number 066220, 2006.

[6] Kelkar, M.A., Gogate, P.R. \& Pandit, A.B., Intensification of esterification of acids for synthesis of biodiesel using acoustic and hydrodynamic cavitation. Ultrasonics Sonochemistry, 15, pp. 188-194, 2008.

[7] Stavarache, C., Vinatoru, M. \& Maeda, Y., Aspects of ultrasonically assisted transesterification of various vegetable oils with methanol. Ultrasonics Sonochemistry, 14(3), pp. 380-386, 2007.

[8] Siatis, N.G., Kimbaris, A.C., Pappas, C.S., Tarantilis, P.A. \& Polissiou, M.G., Improvement of biodiesel production based on the application of ultrasound: monitoring of the procedure by FTIR spectroscopy. Journal of the American Oil Chemists Society, 83(1), pp. 53-57, 2006.

[9] Hanh, H.D., Dong, N.T., Starvarache, C., Okitsu, K., Maeda, Y. \& Nishimura, R., Methanolysis of triolein by low frequency ultrasonic irradiation. Energy Conversion and Management, 49, pp. 276-280, 2008.

[10] Stavarache, C., Vinatoru, M., Nishimura, R. \& Maeda, Y., Fatty acids methyl esters from vegetable oil by means of ultrasonic energy. Ultrasonics Sonochemistry, 12, pp. 367-372, 2005.

[11] Colucci, J.A., Borrero, E.E. \& Alape, F., Biodiesel from an alkaline transesterification reaction of soybean oil using ultrasonic mixing. Journal of the American Oil Chemists Society, 82(7), pp. 525-530, 2005.

[12] Stavarache, C., Vinatoru, M. \& Maeda, Y., Ultrasonic versus silent methylation of vegetable oils. Ultrasonics Sonochemistry, 13(5), pp. 401-407, 2006.

[13] Lidstrom, P., Tierney, J., Wathey, B. \& Westman, J., Microwave assisted organic synthesis - a review. Tetrahedron, 57, pp. 9225-9283, 2001.

[14] Varma, R.S., Solvent-free accelerated organic syntheses using microwaves. Pure and Applied Chemistry, 73(1), pp. 193-198, 2001.

[15] Koopmans, C., Iannelli, M., Kerep, P., Klink, M., Schmitz, S., Sinnwell, S. \& Ritter, H., Microwave-assisted polymer chemistry: Heck-reaction, transesterification, Baeyer-Villiger oxidation, oxazoline polymerization, acrylamides, and porous materials. Tetrahedron, 62(19), pp. 4709-4714, 2006.

[16] Saifuddin, N. \& Chua, K.H., Production of ethyl ester (biodiesel) from used frying oil: optimization of transesterification process using microwave irradiation. Malaysian Journal of Chemistry, 6(1), pp. 77-82, 2004. 
[17] Mazzocchia, C., Modica, G., Nannicini, R. \& Kaddouri, A., Fatty acid methyl esters synthesis from triglycerides over heterogeneous catalysts in the presence of microwaves. Comptes Rendus Chimie, 7(6-7), pp. 601-605, 2004.

[18] Hernando, J., Leton, P., Matia, M.P., Novella, J.L. \& Alvarez-Builla J., Biodiesel and FAME synthesis assisted by microwaves: Homogeneous batch and flow processes. Fuel, 86, pp. 1641-1644, 2007.

[19] Leadbeater, N.E. \& Stencel, L.M., Fast, easy preparation of biodiesel using microwave heating. Energy and Fuels, 20, pp. 2281-2283, 2006.

[20] Barnard, T.M., Leadbeater, N.E., Boucher, M.B., Stencel, L.M. \& Wilhite, B.A., Continuous-flow preparation of biodiesel using microwave heating. Energy and Fuels, 21, pp. 1777-1781, 2007. 